\title{
Incidence of Preeclampsia in Albanian women, estimated in “Mbretëresha Geraldinë” Hospital in period 2015-2017
}

\author{
Demaliaj Eliona ${ }^{1}$ \\ Hoxha Eden² \\ ${ }^{1}$ Gynecology and Obstetrics, Ass. Prof. Medical University of Tirana, Tirana, Albania \\ ${ }^{2}$ Gynecology and Obstetrics, Matrix Medical Centre, Tirana, Albania
}

\section{Introduction:}

Preeclampsia is a hypertensive disorder with a multi-organ affection, that affects $3-5 \%$ of all pregnancies. Preeclampsia is a major cause of maternal morbidity and mortality, preterm labor, perinatal mortality and foetal hypertrophy.

\section{Methods and patients:}

We carried a retrospective study at "Mbretëresha Geraldinë" Maternity Hospital, by calculating statistically all the births of women with Preeclampsia that gave birth at "Mbretëresha Geraldinë" Maternity in, year 2015, 2016 and January-March of 2017.

432 pregnant women with Preeclampsia were followed up. After a meta-analysis, we established the incidence of this disorder in Albania, how women's age affects the incidence of Preeclampsia, the distribution of this incidence between primiparous and multiparous women, the incidence of Preeclampsia related complications in pregnant women, maternal morbidity and mortality and foetal mortality, foetal prematurity and it's birth weight.

\section{Results:}

The incidence of Preeclampsia in 2015 was $2.66 \%$, in 2016 it was $3.14 \%$ and so far in 2017 it is $1.6 \%$. The most common age group between women hospitalized because of Preeclampsia related disorders, for the 3 years taken into account, is 25 and 26 years old.

Incidence of Preeclampsia in Albanian women, 2015, 2016 and January-March 2017

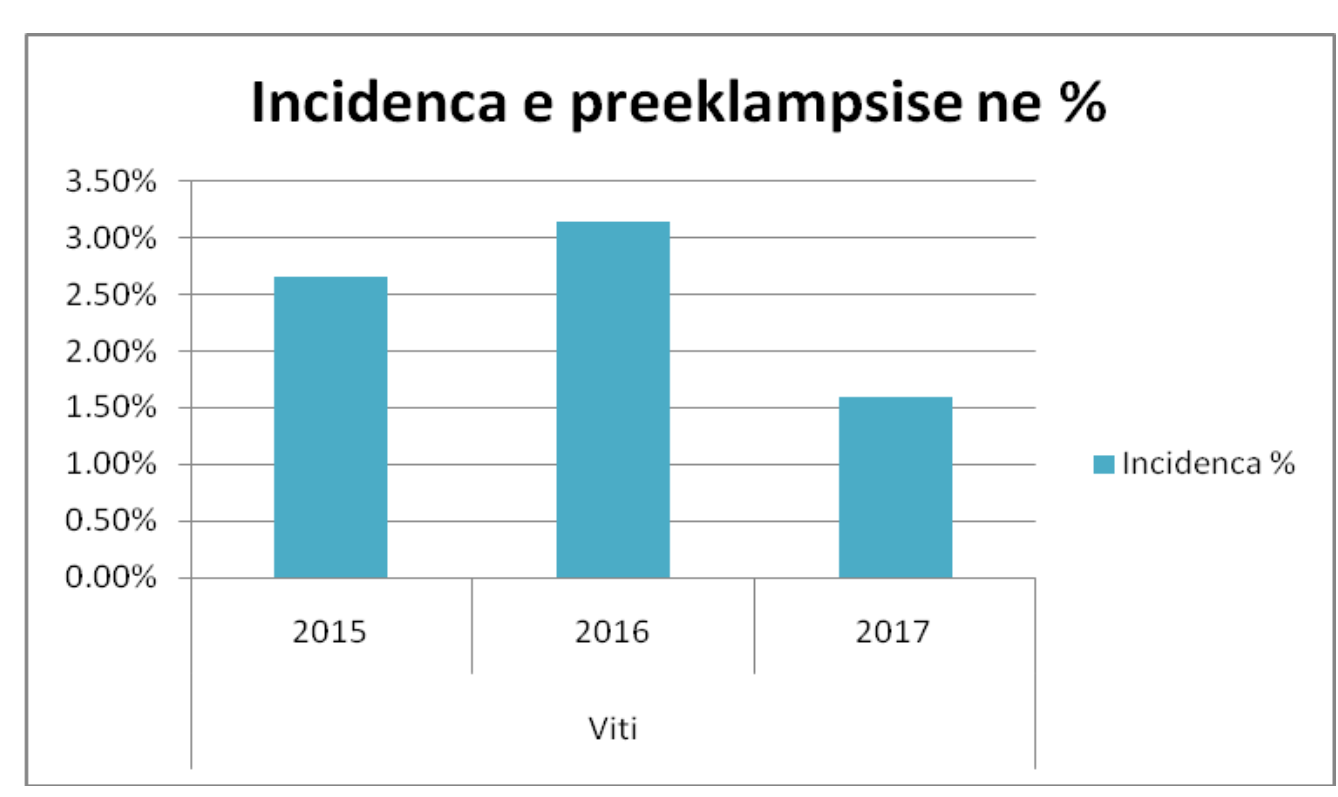

Regarding the incidence of Preeclampsia, it is clear that there is a higher incidence in younger pregnant women (15-18 years old) and older women (37-41 years old). The highest incidence, in 144 births, is estimated in primiparous women with Preeclampsia. A lower incidence is noticeable in pluriparous women, with the percentage lowering with every birth. From statistical evidences, the highest percentage of gestational age is the one on full term; specifically, 161 women gave birth on time (36-42 gestational week) for year 2015, 182 women for year 2016 and 30 women for JanuaryMarch period in 2017.

\section{Conclusions:}

Preeclampsia is a rare pregnancy related disorder, with an unpredictable course, that can be fatal for the mother and the child. The incidence of the disease in "Mbretëresha Geraldinë" Maternity, in the years that we took into consideration, was approximately 2.6 .

\section{How women's age affects the percentage of Preeclampsia}

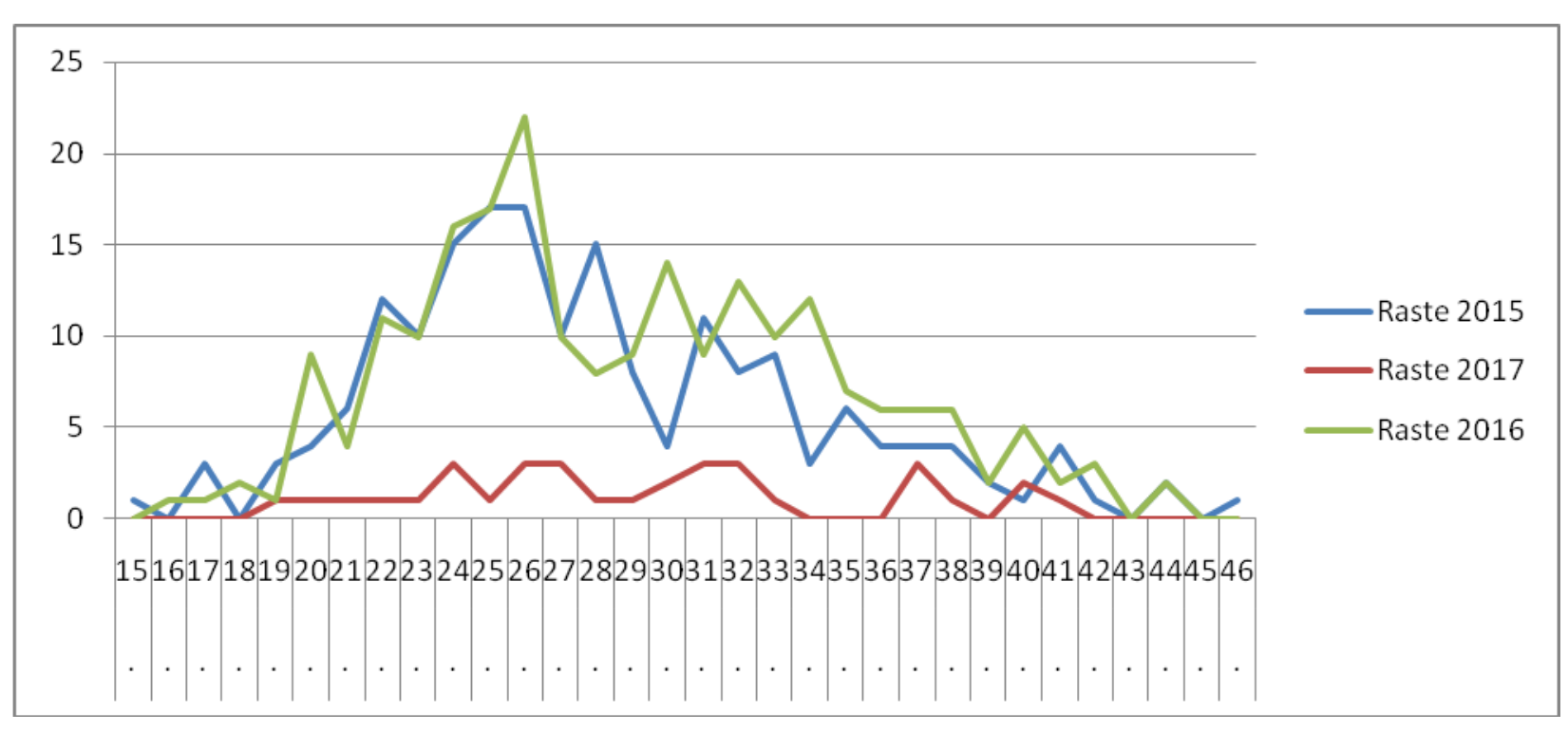

